\title{
Clinicopathologic Study of Tongue Lesions at a Tertiary Care Hospital
}

\author{
Srivani Narala ${ }^{1}$, Swarna Sri $^{2}$ \\ ${ }^{1}$ Department of Pathology, Osmania Medical College, Hyderabad, Telangana, India. \\ ${ }^{2}$ Department of Pathology, Osmania Medical College, Hyderabad, Telangana, India.
}

\section{ABSTRACT}

\section{BACKGROUND}

Tongue lesions constitute a considerable proportion of oral mucosal lesions. Varying pathologic conditions may affect the tongue of which chronic lesions often necessitate biopsy and histological diagnosis. Most of the studies are based on clinical presentation of tongue lesions or histopathological study of oral cavity lesions as a whole. There are limited studies on clinico-pathologic review of histologically diagnosed tongue lesions which are mostly case specific. Lesions of tongue encompass a diverse spectrum of non-neoplastic and neoplastic entities. Varying pathologic conditions may affect the tongue of which chronic lesions often necessitate biopsy. Clinico-pathological correlation with microscopic examination helps in accurate diagnosis and management of patients.

\section{METHODS}

This retrospective study included 192 tongue biopsies, and was conducted over a period of one year from January 2018 to December 2018 at a tertiary ENT hospital. Data on age, gender, tobacco usage, site distribution, type of lesion and histological diagnosis was analysed.

\section{RESULTS}

Tongue lesions were seen in 133 males and 59 females. The predominant age group affected was the $5^{\text {th }}$ decade of life accounting for 40 cases $(20.8 \%)$. Biopsies of ulceroproliferative type of lesions were most commonly submitted. Neoplastic lesions constituted 137 cases $(71.3 \%)$ of total cases of which well differentiated squamous cell carcinoma was the most common malignant lesion accounting for 85 cases $(44.2 \%)$. Using the WHO ICD-O code for topography of lesions, the tongue lateral border (ICD-0-2.1) was the most commonly affected site in the present study.

\section{CONCLUSIONS}

Tongue lesions are relatively common in our environment with male predilection, above 40 years age group, strong association with tobacco usage, a predominance of neoplastic lesions, predilection for the lateral border of the tongue and squamous cell carcinoma as the most common histological diagnosis. The high frequency of tongue involvement emphasizes the importance of early adequate biopsy of elementary lesion. Histological characterization can help the clinician in planning early successful management of cases.

\section{KEY WORDS}

Tongue Lesions, Elementary Lesion, Squamous Cell Carcinoma

\author{
Corresponding Author: \\ Swarna Sri, \\ Flat No. 101, Tirumala Sravani Apts., \\ RD. No. 1, Alkapuri SRK Puram, \\ Saroornagar-500102, P. O. Rangareddy, \\ Telangana, India. \\ E-mail: swarna.lakme@gmail.com
}

DOI: 10.14260/jemds/2020/184

Financial or Other Competing Interests: None.

How to Cite This Article: Narala S, Sri S. Clinicopathologic study of tongue lesions at a tertiary care hospital. J. Evolution Med. Dent. Sci. 2020;9(11):856859, DOI: 10.14260/jemds/2020/184

Submission 28-12-2019,

Peer Review 20-02-2020,

Acceptance 26-02-2020,

Published 16-03-2020.

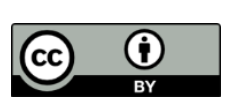




\section{BACKGROUND}

Tongue lesions constitute a considerable proportion of oral mucosal lesions. Varying pathologic conditions may affect the tongue of which chronic lesions often necessitate biopsy and histological diagnosis. ${ }^{1}$ Most of the studies are based on clinical presentation of tongue lesions or histopathological study of oral cavity lesions as a whole. There are limited studies on clinico-pathologic review of histologically diagnosed tongue lesions which are mostly case specific. ${ }^{2,3,4}$ The tongue is commonly affected by non- neoplastic and neoplastic lesions, the latter usually being characterized by a progressive growth that can be either benign or malignant. Non-neoplastic lesions are either inflammatory or represent a reaction to diverse types of irritative stimuli and are often discovered accidentally during routine oral examination. ${ }^{5}$ The present study reviews the clinico-pathologic features and histological diagnosis of tongue lesions that was presented in a tertiary care hospital. Lesions of tongue in the present study on histopathology showed non-neoplastic, premalignant and neoplastic lesions.

Histopathologically, non-neoplastic lesions of tongue in the present study showed pyogenic granuloma, mucus retention cysts, mucus extravasation cysts, angiokeratoma circumscriptum and lingual thyroid. These lesions presented as polypoidal or cystic masses. Pyogenic granuloma is one of the inflammatory hyperplasias, presenting as a smooth or lobulated exophytic lesion. Microscopic examination showed a highly vascular proliferation with numerous small channels lined by endothelial cells and red blood cells in lumen. Mucus retention cysts occur due to obstruction of minor salivary gland excretory duct of tongue. Microscopy showed an epithelial cyst lining and filled with mucin. Mucus extravasation cysts presenting as a small nodule, on microscopy showed extravasated mucin and no epithelial cyst lining. Angiokeratoma circumscriptum is a rare vascular malformation presented as red papules on dorsum of tongue. Microscopy showed parakeratosis, acanthosis, papillomatosis with large dilated spaces lined by endothelium and filled with erythrocytes and organizing thrombi. Lingual thyroid is a developmental anomaly with ectopic thyroid tissue and presented as a mass at base of tongue. Microscopy showed thyroid tissue beneath the squamous epithelium of tongue.

Premalignant lesions presenting as a white patch or leukoplakia on histology showed hyperkeratosis with varying degrees of dysplasia and oral proliferative verrucous leukoplakia (OPVL). Dysplasia showed an abnormal epithelial growth with cytologic, maturational and architectural changes. In severe dysplasia most of the epithelium is involved and heralds a greater risk for malignant transformation. Oral proliferative verrucous leukoplakia on histology showed hyperkeratosis, verrucous hyperplasia and epithelial dysplasia. Benign tumours of tongue include fibroepithelial polyp, squamous papilloma and schwannoma. Fibroepithelial polyp presented as a small red knob-like growth on dorsum of tongue. Microscopy showed fibrovascular core and loose collagen covered by squamous epithelium. Squamous papilloma of tongue showed hyperplastic epithelium with papillomatosis, parakeratosis, koilocytic change and a fibrovascular core. Schwannoma of tongue presented as a slow growing lump on right lateral border of tongue, histologically showed a well encapsulated tumour with hypercellular spindle cell areas (Antoni A) and hypocellular small round cells (Antoni B) within a myxoid stroma.

Malignant tumours include squamous cell carcinoma (SCC) and mucoepidermoid carcinoma (MEC). Exophytic or ulceroproliferative lesions and ulcerative lesions on histology showed well differentiated squamous cell carcinoma as the most common lesion. Tongue squamous cell carcinoma was commonly seen in middle aged and elderly males. The incidence is related to tobacco use, chewing and smoking, betel nut chewing and alcohol consumption. Squamous cell carcinoma involved anterior two thirds of tongue with lateral border as the most common site of involvement. Mucoepidermoid carcinoma presenting as an exophytic lesion over base of tongue on histology showed solid areas of epidermoid cells and few mucous cells.

\section{METHODS}

This is a retrospective study of tongue lesions seen over a period of one year from January to December 2018 done in the Department of Pathology at tertiary ENT hospital. Based on the clinical appearance or type of elementary lesion, categorisation into ulceroproliferative, ulcerative, leukoplakia, polypoidal and cystic masses has been done. Subsequently, histological diagnosis of each type of lesion is done. Site of lesions were coded using the WHO ICD-O code 6 on topography. Haematoxylin and eosin sections of each biopsy were evaluated by light microscopy. The study was approved by Ethical Committee and informed consent was obtained.

All incisional and wedge biopsies of adequate and representative tongue lesions are included from all age groups both males and females with complete and satisfactory clinical details and case histories were included in the study. Inadequate biopsies were excluded from the study.

\section{Statistical Analysis}

The Statistical Package for Social Science \{SPSS Version 20 will be used for Data Analysis Data on age, gender, site distribution, type of elementary lesion and histological diagnosis were analysed using frequencies, ranges and percentage of total cases. Variables were compared using Chi square test.

\begin{tabular}{|ccc|}
\hline \multicolumn{3}{|c|}{ RESUL T S } \\
\hline Age Range (in Years) & Males (Number of Cases) & Females \\
$<10$ & 2 & 4 \\
$10-19$ & - & 1 \\
$20-29$ & 8 & - \\
$30-39$ & 31 & 6 \\
$40-49$ & 33 & 7 \\
$50-59$ & 17 & 16 \\
$60-69$ & 24 & 15 \\
$70-79$ & 14 & 10 \\
$80-89$ & 4 & - \\
Total & $\mathbf{1 3 3}$ (69.3\%) & $\mathbf{5 9}(\mathbf{3 0 . 7} \%)$ \\
\hline Table 1. Age Group and Gender Distribution of Tongue Lesions \\
\hline
\end{tabular}


A total of 1580 biopsy cases were diagnosed during the study period (January 2018 to December 2018) of which 192 cases $(12.1 \%)$ were tongue lesions.

\begin{tabular}{|ccc|}
\hline Type of Lesion & Number of Cases & Percentage (\%) \\
Ulceroproliferative growth & 130 & 67.7 \\
Ulcer & 41 & 21.3 \\
Polypoidal mass & 10 & 5 \\
Leukoplakia & 7 & 3.6 \\
Cyst & 4 & 2 \\
\hline Table 2. Distribution of Cases Based on Clinical Presentation \\
\hline
\end{tabular}

\begin{tabular}{|ccc|}
\hline Histopathological Diagnosis & Number of Cases & (\%) \\
Well differentiated SCC & 72 & 37.5 \\
Moderately differentiated SCC & 31 & 16.1 \\
Poorly differentiated & 3 & 1.5 \\
Verrucous Hyperplasia & 9 & 4 \\
Severe dysplasia & 4 & 2 \\
Keratotic dysplasia & 2 & 1 \\
Pseudoepitheliomatous Hyperplasia & 2 & 1 \\
Basaloid SCC & 2 & 1 \\
MEC & 1 & 0.5 \\
OPVL & 1 & 0.5 \\
Fibroepithelial Polyp & 1 & 0.5 \\
Lingual Thyroid & 1 & 0.5 \\
Squamous Papilloma & 1 & 0.5 \\
\hline SCC-Squamous cell carcinoma, MEC-Mucoepidermoid Carcinoma, OPVL-Oral \\
Proliferative Verrucous Leukoplakia & & \\
\hline Table 3A. Histopathological Diagnosis of Ulceroproliferative Lesions \\
\hline Histopathological Diagnosis & Number of Cases & $\mathbf{( \% )}$ \\
Well Differentiated SCC & 13 & 6.7 \\
Moderately Differentiated SCC & 8 & 4.1 \\
Nonspecific Ulcer & 9 & 4.6 \\
Severe Dysplasia & 4 & 2 \\
Verrucous Hyperplasia & 5 & 2.6 \\
Keratotic Dysplasia & 2 & 1 \\
Squamous Papilloma & 1 & 0.5 \\
\hline Table 3B. Histopathological Diagnosis of Ulcerative Lesions \\
\hline
\end{tabular}

\begin{tabular}{|ccc|}
\hline Histopathological Diagnosis & Number of Cases & (\%) \\
Pyogenic Granuloma & 4 & 2 \\
Squamous Papilloma & 2 & 1 \\
Hyperplastic Epithelium & 1 & 0.5 \\
Schwannoma & 1 & 0.5 \\
Angiokeratoma Circumscriptum & 1 & 0.5 \\
MEC & 1 & 0.5 \\
\hline Table 4A. Histopathological Diagnosis of Polypoidal Mass \\
\hline Histopathological Diagnosis & Number of Cases & $(\%)$ \\
Dysplasia & 4 & 2 \\
Hyperkeratotic Epithelium & 2 & 1 \\
OPVL & 1 & 0.5 \\
\hline Table 4B. Histopathological Diagnosis of Leukoplakia \\
\hline Histopathological Diagnosis & Number of Cases & $(\%)$ \\
Mucus Retention Cyst & 2 & 1 \\
Mucus Extravasation Cyst & 2 & 1 \\
\hline Table 4C. Histopathological Diagnosis of Cystic Lesions \\
\hline \multicolumn{3}{|c}{} \\
\hline \multicolumn{2}{|c}{} \\
\hline
\end{tabular}

\begin{tabular}{|ccc|}
\hline Site & Number of Cases & Percentage (\%) \\
Base of tongue & 30 & 22.7 \\
Dorsum & 13 & 6.7 \\
Border & 132 & 68.7 \\
Ventral surface & 9 & 4.6 \\
Overlapping & 8 & 4.1 \\
\hline Table 5. ICD-O Site Distribution of Tongue Lesions & $\mathbf{6}$ \\
\hline ICD-O: International Classification of Diseases-Oncology \\
\hline
\end{tabular}

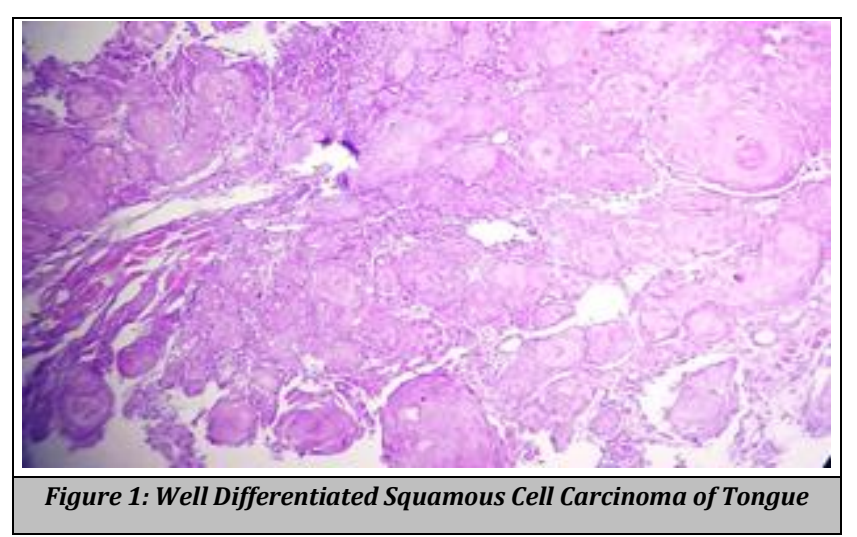

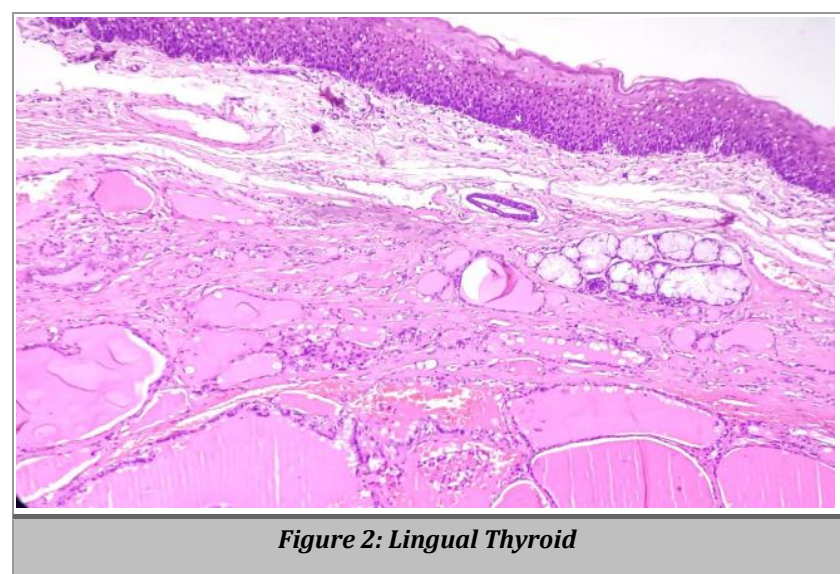

\section{DISCUSSION}

This present study represents frequency and distribution of biopsied lingual lesions at a tertiary care hospital. There are limited studies on the frequency of oral diseases exclusively on tongue. Tongue lesions constituted $12.1 \%$ of the total biopsied lesions in 2018 at our institute contributing to a significant proportion of cases. The prevalence of tongue lesions was $3.7 \%$ in Iranian patients 7 in a study done by Nafiseh Shamloo et al (2017) and 4\% in Nigerian patients 8 in a study done by T. J. Lasisi et al (2017).This difference may be attributed to variations in geographic distribution, ethnicity, habits and sample size. In the present study, males (69.3\%) were affected more than females (30.7\%).Similar findings were noted by studies done by Nafiseh Shamloo et al (2017) and Costa et al (2012). ${ }^{9}$ With respect to age distribution, tongue lesions were found more commonly in patients between 41-69 years of age (58.3\%), which was comparable to studies done by T.J. Lasisi et al (2017) and Kantola et al ${ }^{10}$ (2001). Our study showed age frequency peaks: this occurred in the fifth decade for males (age 40-49) and in the sixth decade for females (age 50-59). This observation shows age frequency peak a decade earlier in our population when compared to study done by Gambino A et al ${ }^{11}$ (2015) in a large Northern Italian population which showed age frequency peaks in sixth decade for males (age 50-59) and in the seventh decade for females (age 60-69).

The present study reveals a strong correlation with tobacco usage in the form of pan, gutka, jarda, smoking and occurrence of squamous cell carcinoma, leukoplakia and oral proliferative verrucous leukoplakia. Tobacco use is causally related to oral cancers and precancerous lesions. It leads to cancer as a result of alterations in cellular growth control processes, together with changes in the interactions between cells and their surroundings which give rise to invasion and metastasis. ${ }^{12}$ Biopsies from ulceroproliferative, ulcerative, polypoidal, cystic lesions and leukoplakia were categorised and studied. Ulceroproliferative lesions (67.7\%) were predominant with well differentiated squamous cell carcinoma $(37.5 \%)$ being the most common histological diagnosis. One case each of basaloid squamous cell carcinoma, mucoepidermoid carcinoma, oral proliferative verrucous leukoplakia (OPVL), fibroepithelial polyp, lingual thyroid and squamous papilloma were encountered. OPVL 
develops initially as a white plaque of hyperkeratosis that eventually becomes a multifocal disease with confluent, exophytic and proliferative features. The buccal mucosa and tongue are the most frequently involved sites. ${ }^{13}$

Biopsy from ulcerative lesions $(21.3 \%)$ also showed well differentiated squamous cell carcinoma $(6.7 \%)$ as the most common histological diagnosis and less common cases of keratotic dysplasia and squamous papilloma were noted. The present study reported 126 cases $(65.6 \%)$ of tongue SCC of which $67.4 \%$ constituted well differentiated histological type. However, study done by Lasisi et al ${ }^{14}$ (2012) reported $79.2 \%$ of well differentiated SCC with a comparatively lesser sample size of 21 cases of tongue SCC. The present study shows ulceroproliferative and ulcerative lesions are associated with squamous cell carcinoma and the necessity for early adequate biopsy of elementary lesion. The association between the elementary lesion that undergoes a biopsy, the biopsy site and the subsequent histopathological diagnosis highlights the fact that certain tongue diseases occur more frequently than others and that they show a specific pattern in a specific preferred site. This observation was made by a study done by Gambino A et al (2015).

Biopsy from polypoidal lesions (5\%) showed pyogenic granuloma, schwannoma, angiokeratoma circumscriptum and MEC on histology. In the present study leukoplakia (3.6\%) on histology showed dysplasia, hyperkeratotic epithelium and OPVL. Cystic lesions (2\%) were least common with mucus retention cysts and mucus extravasation cysts on histology. Squamous cell carcinoma (65.6\%) was the most common tongue lesion in the present study and higher comparable to studies done by Lasisi et al (2017) (40.5\%) and Hernandez-Guerreroet al ${ }^{15}$ (2013) (44.7\%). Topographically SCC occured most frequently on the lateral border of the tongue in the present study which is comparable to study done by Nafeseh et al (2017). However study done by Lasisi et al (2017) showed dorsum and anterior two-thirds of the tongue as the most common site of involvement.

\section{CONCLUSIONS}

Tongue lesions are relatively common in our environment with male predilection, in above 40 years age group, strong association with tobacco usage, a predominance of neoplastic lesions, predilection for the lateral border of the tongue and squamous cell carcinoma as the most common histological diagnosis. The high frequency of tongue involvement emphasizes the importance of early adequate biopsy of elementary lesion. Histological characterization can help the clinician in planning early successful management of cases.

\section{REFERENCES}

[1] Logan RM, Goss AN. Biopsy of the oral mucosa and use of histopathology services. Aust Dent J 2010;55(1 Suppl):913.

[2] Lau SK, Bishop JA, Thompson LDR. Spindle cell lipoma of the tongue: a clinicopathologic study of 8 cases and review of the literature. Head Neck Pathol 2015;9(2):253-9.

[3] Koutlas IG, Scheithauer BW. Palisaded encapsulated ("solitary circumscribed") neuroma of the oral cavity: a review of 55 cases. Head Neck Pathol 2010;4(1):15-26.

[4] Diapera MJ, Lozon CL, Thompson LDR. Malacoplakia of the tongue: a case report and clinicopathologic review of 6 cases. Am J Otolaryngol 2009;30(2):101-5.

[5] Reamy BV, Derby R, Bunt CW. Common tongue conditions in primary care. Am Fam Physician 2010;81(5):627-34.

[6] Fritz A, Percy C, Jack A, et al. WHO. International classification of diseases for Oncology (ICD-0). $3^{\text {rd }}$ edn. 1st revision, 2013: p. 33.

[7] Shamloo N, Lotfi A, Motazadian HR, et al. Squamous cell carcinoma as the most common lesion of the tongue in Iranians: a 22-year retrospective study. Asian Pacific Journal of Cancer Prevention 2016;17(3):1415-9.

[8] Lasisi TJ, Abimbola TA. Clinico-pathologic review of biopsied tongue lesions in a Nigerian tertiary hospital. Annals of Ibadan Postgraduate Medicine 2017;15(2):109-13.

[9] Costa FWG, Osterne RLV, Mota MRL, et al. Tongue lesions. J Craniofac Surg 2012;23(6):e548-51.

[10] Kantola S, Jokinen K, Hyrynkangas K, et al. Detection of tongue cancer in primary care. $\mathrm{Br} \mathrm{J}$ Gen Pract 2001;51(463):106-11.

[11] Gambino A, Carbone M, Arduino PG, et al. Clinical features and histological description of tongue lesions in a large Northern Italian population. Med Oral Patol Oral Cir Bucal 2015;20(5):e560-5.

[12] Mishra N, Shrivardhan K, Jayesh R, et al. Tobacco related lesions of oral cavity - a review. International Journal of Contemporary Medicine Surgery and Radiology 2017;2(1):25-8.

[13] Issrani $\mathrm{R}$, Prabhu N, Keluskar V. Oral proliferative verrucous leukoplakia: a case report with an update. Contemporary Clinical Dentistry 2013;4(2):258-62.

[14] Lasisi TJ, Adeyemi BF, Oluwasola AO, et al. Oro-facial squamous cell carcinoma - a twenty-year retrospective clinicopathological study. Afr J Med Med Sci 2012;41(3):265-70.

[15] Hernandez-Guerrero JC, Jacinto-Aleman LF, JimenezFarfan MD, et al. Prevalence trends of oral squamous cell carcinoma. Mexico City's General Hospital experience. Med Oral Patol Oral Cir Bucal 2013;18(2):306-11. 